\title{
Vehicle-to-grid service development logic and management formulation
}

\author{
Lefeng $\mathrm{SHI}^{1}$ (1), Tong $\mathrm{LV}^{1}$, Yandi $\mathrm{WANG}^{2}$
}

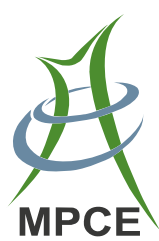

\begin{abstract}
Vehicle-to-grid (V2G) is regarded as the effective way to reconcile contradictions between an electric power system and electric vehicles (EVs). A lot of research has been carried out to affect this, often based on different technical and trading model assumptions. The value of the research is dependent on how reasonable the assumptions it makes are. This paper presents a framework for analyzing V2G service development from a coevolutionary perspective in which the interactive relation between the diffusion of EVs and the upgrade of the distribution grid system is considered. A V2G service development logic and its management formulation are put forward. First, the motivations and contradictions of developing V2G services are analyzed. Then a development phase division of the V2G services is proposed in view of the coevolution relation between the grid upgrade and the development of the EV. Next, taking into account the characteristics of each phase, the physical trade structures and corresponding management hierarchies, management relations as well as
\end{abstract}

CrossCheck date: 6 September 2018

Received: 21 February 2018/ Accepted: 6 September 2018/Published online: 14 November 2018

(c) The Author(s) 2018

$\triangle$ Lefeng SHI

shilefeng@foxmail.com

Tong LV

lvtong527@163.com

Yandi WANG

17853142708@163.com

1 School of Economics and Management, Chongqing Normal University, Chongqing 401331, China

2 School of Electrical Engineering, Shandong University, Jinan 250061, China management measures, are proposed. This paper provides a new perspective of $\mathrm{V} 2 \mathrm{G}$ service development, answers the core question on how to make the $\mathrm{V} 2 \mathrm{G}$ vision come true in synergy with the development of EVs, and gives some advice on future V2G management paradigms.

Keywords Electric vehicle, Vehicle-to-grid service, Evolution, Smart grid, Aggregator

\section{Introduction}

The electric vehicle (EV) is seen as an important part of the future smart grid. This is expected to play a promising role in fine-tuning the power fluctuation of the electric power system as an ancillary service provider, due to its two advantages. First, the long parking time ( $23 \mathrm{~h}$ per day on average) provides the necessary precondition for the grid system operator (GSO) to control the charging or discharging power of an EV's battery for vehicle-to-grid (V2G) services [1], i.e. balancing the voltage frequency [2], absorbing excessive renewable energy $[3,4]$ and supplying other ancillary services. Second, depending on exploiting V2G services rather than using other conventional facilities, a GSO could avoid the extra construction investment in either peak generators or special storage equipment, because it need not invest in the EV directly $[5,6]$. All these make EV's V2G services attractive.

$\mathrm{V} 2 \mathrm{G}$ refers to the interaction between $\mathrm{EVs}$ and the power grid. The basic idea of $\mathrm{V} 2 \mathrm{G}$ is to use $\mathrm{EV}$ batteries as the intermediate storage facilities for providing services to the electric power system when EVs are parked [7]. The concept of V2G was first introduced in 1997 [8], and this transformed our original understanding of the influence of EVs on the electric power system. In the beginning, some 
worried that the increment of EVs would bring a big challenge to the electric power system in terms of power provision, system stability and so on $[9,10]$; however, from the perspective of V2G, EVs are not a burden but a beneficial resource. The grid system could become more economic than currently if the potential of V2G services is exploited properly; in the meantime EV owners and GSO could each obtain benefit, not only from the extra revenue but also by enhancing the efficiency of asset usage.

V2G sparked a lot of research in the two decades after being proposed. Various theoretical investigations were undertaken to examine its effectiveness and many optimization methods were proposed to support its implementation. As far as the technology is concerned, due attention has been paid so far to realize the V2G service version under various scenario assumptions [11]. Some controlling algorithms were designed in relation to the current power system. These pursued the minimization of system loss [12], balance of power supply-demand as well as the optimal allocation of EV charging stations [13, 14]; some considered the above problems in the environment of the smart grid [15]; other works took the absorption of renewable resource and/or the benefit of EV owners (e.g. the life of batteries) into account [16].

For management schemes, many suggestions were made based on different management objectives. From the perspective of energy management strategies, the major subjects are: designing smart load management strategies for coordinating EV charging based on minimizing the negative influence of charging [17] or in the context of new electricity price environments [18], designing demand side management (DSM) strategies under special technical situations [19], and proposing an operational method considering EV battery degradation [20]. The other part focuses on trade model design, including management structure design [21, 22] and short-time trade model building [23, 24], in which EVs are always seen as special parts of the smart grid or agented by an aggregator. Reference [23] proposed a market trading paradigm of the V2G reserve. Reference [25] presented an optimal bidding strategy of V2G service aggregators in day-ahead electricity markets, assuming the aggregators were risk-averse in the face of uncertainty. Also some researchers began to analyze the relevant problems using game theory. For example, [26, 27] employed game theory to analyze the interplay of EV owners and the utility company; [28] proposed a new practical demand response (DR) program for EVs' charging schedule based on a game theoretic approach, aimed at optimizing customers' charging cost.

In summary, a body of valuable research has been done around the topic of V2G. However, the majority of it is based on different hypothetical scenarios and assumptions. Whether the scenarios and assumptions are reasonable determines their academic value. After conducting a comprehensive analysis, we find that much of existing research is valid in special situations which lie in different developing phases of both power system and EVs. Nonetheless, little research has described the development process of $\mathrm{V} 2 \mathrm{G}$ services from a holistic perspective. This lack makes it difficult to evaluate the suitability of different pieces of research. As such, it seems meaningful to make clear the development logic of V2G services and describe the relevant management formulation explicitly.

This paper aims to delineate an implementation logic and corresponding management framework of V2G services, in which both the grid system upgrade and the diffusing of EVs are taken into account. The contributions of the paper are fourfold: (1) the developing phases of $\mathrm{V} 2 \mathrm{G}$ services are divided; (2) the management architectures of different phases are proposed; (3) the management relations of different phases are depicted; (4) the management measures suitable for each phase are analyzed.

The rest of this paper is organized as follows: after summarizing the motivations and contradictions of developing V2G services in Section 2, the dynamic development process of $\mathrm{V} 2 \mathrm{G}$ services is divided into three phases in Section 3; Section 4 is devoted to analyzing the management formulation of different phases involving management architectures, management relations, and management measures; the discussion and conclusion are provided in Sections 5 and 6.

\section{Motivations and contradictions of developing V2G services}

\subsection{Motivations}

Two stakeholders have close relations with V2G services, i.e. GSO and EV owners. They will have different motivations. How to satisfy their need for benefits meantime, is key to realize V2G services. Hence, the first step of this paper is to distinguish the motivations of stakeholders.

\section{1) Motivations of GSO}

The primary motivation of GSO is to avoid the potential operational risk of the distribution grid. This risk will increase the more pervasive EVs are. A lot of research shows that the uncontrolled charging of EVs could heavily affect the operation of the distribution grid system. Reference [29] argued that the introduction of EVs could impact demand peaks, reduce reserve margins, and increase the operating cost of the grid system. However, [30] argued that these challenges will stimulate the distribution grid system to transform from a "passive grid" to an "active grid", in which EVs are not a troublemaker but 
V2G service providers. In ideal V2G service scenarios, the EVs could play a role as the renewable resource absorbers and the frequency regulators as well as other ancillary service suppliers. The operational cost of a GSO would decrease by virtue of the merits of the V2G service; furthermore resilience of the distribution grid would also be enhanced.

\section{2) Motivations of EV owners}

Without doubt, the main motivation of EV owners who join V2G services is to decrease their charging cost or to get discharging revenue $[1,31]$. However, another condition must also be satisfied before EV owners choose to provide V2G services. That is that the negative implications of $\mathrm{V} 2 \mathrm{G}$ i.e. a driving limit and degradation of $\mathrm{EV}$ batteries, should lie within an acceptable range [32]. These preconditions will impact the charging-discharging behaviors of EV owners. For example, it was concluded that 40 miles of charge depleting range are necessary for an average EV if no infrastructure is available [26]. Nonetheless, a rich charging infrastructure can reduce the peak load caused by charging in different hours of the day or night [33].

\subsection{Contradictions}

Different stakeholders have different motivations for propelling V2G services, and some latent contradictions stemming from these cannot be ignored.

\section{1) Instability versus high response}

V2G services are more likely to be unstable compared with the traditional ancillary services from generators which opt to establish a stable interfirm relationship $[34,35] . \mathrm{EV}$ is a transportation tool essentially, so charging-discharging behaviors of its owner might be easily disturbed by the stochastic change of driving schedule or other random factors. Moreover, the limited capacity of an EV's batteries cannot support long-duration services as do the conventional ancillary service generators. Nevertheless, a V2G service still has important advantages, e.g. high response speed and a short distance to the loads, making it superior to a generation side ancillary service in some situations.

\section{2) Buyer's monopoly trade versus guiding force}

The trade of a V2G service might be a buyer's monopoly trade. The GSO or aggregator has strong bargaining power to influence the behavior of EV owners through price strategy or other incentives. EV owners would be a price-taker since its capacity of supplying V2G service is too small to influence the trading behavior of a GSO or aggregator. That makes the GSO or aggregator better able to influence the charging-discharging behavior of $\mathrm{EV}$ owners to mitigate the negative impact of charging and make the best use of $\mathrm{V} 2 \mathrm{G}$ services [28]. Nonetheless, it also is possible that a GSO might infringe the benefit of EV owners depending on its monopoly position, e.g. by price discrimination [36].

3) Trade benefit versus flexibility limitation

A V2G service provides an opportunity for EV owners to get extra benefits and take full advantage of their assets (electric vehicles). So putting a V2G service into effect may be a win-win situation both for the GSO and for EV owners. However, taking the opportunity cost of losing the using right of EVs into consideration, EV owners may not like to share EVs for V2G services actively. In addition, because the information asymmetry phenomenon exists, the private information of EV owners is hardly obtained. For example, the temporary need for using EVs is difficult to forecast for a GSO [37]; on the other hand, the expected revenue is hard to determine beforehand, because of the uncertainty of grid demand. This would bring a sense of uncertainty to EV owners [38]. Hence, if the information asymmetry phenomenon cannot be solved well, the promising win-win situation would become a lose-lose situation. So strengthening the coordination between GSO and $\mathrm{EV}$ owners to overcome the information opacity is necessary.

\section{Phase division of V2G service development}

\subsection{Ratiocination of coevolutionary process}

The development of the contents of V2G services may showcase a dynamic process if we see the GSO as a rational decision maker. The rational decision maker does not find it possible to update all the technical equipment for V2G services when the number of EVs is still small. As Fig. 1 shows, the quantity of EVs is so small in the

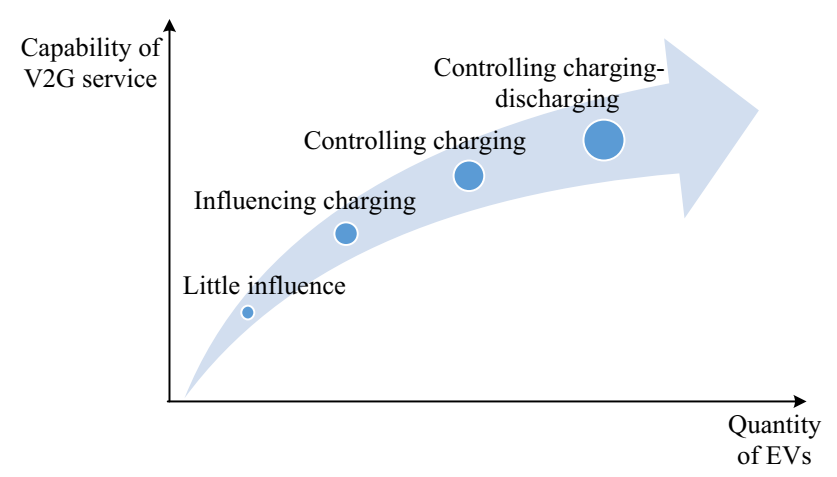

Fig. 1 Coevolution of both V2G services and grid 
beginning that the impact of EV charging could be negligible. With the diffusion of EVs, the influence of EVs is hard to simply neglect [39]. To cope with the impact, a GSO needs to update the grid, add charging infrastructure and choose a proper charging price strategy to obtain the desired charging time choice by EV owners. As the scale of EVs becomes larger and the distribution grid becomes smarter, more complicated management strategies would be employed by a GSO to explore the potential capability of a V2G service. Reference [40] analyzed the endogenous motivation of a GSO to update the distribution grid system and to offer V2G service facilities. It argued that the implementation of the charging/discharging infrastructures for EVs offers a substantial new business opportunity. For the electric power system, "smart" vehicle charging costs $19 \%$ less than serving uniform load growth, while completely uncontrolled charging costs $24 \%$ more [41]. It is completely rational for a DSO to use these savings to invest in the technologies needed to enable smart charging or to provide customer incentives that promote controlled charging. As such, the application of V2G services is not only driven by necessity but also pushed by the prospect of economic effectiveness for the GSO.

For EV owners, because of "range anxiety" incurred by the limited capacity of the EV battery and by any deficiency in charging-discharging facilities, they will be unwilling to join V2G services at the initial stage [42]. However, if the obstacles are removed, EV owners will gradually accept and participate in V2G services [43]. Hence the development process of V2G services is not only the consequence of the mutual influence of EVs and the electric power system but also can be seen as a coevolution process [44]. The logic of the coevolution is that the diffusion of EVs, spurred by the development of EV battery technology, will motivate the GSO and aggregators to upgrade the distribution grid system and to add chargingdischarging infrastructures for V2G services.

\subsection{Classification of V2G services}

There is presently no uniformly accepted definition of V2G services, partly because the scale of EVs and the development of smart grid technologies influence the choice of $\mathrm{V} 2 \mathrm{G}$ service modes. When the technological environment transforms into smart grids, the role of EV owners will change from the power end-users at the initial stage to "prosumers". During this process, the content of V2G services would also evolve. There are three kinds of V2G service instruments which are usually analyzed by the majority of researchers. The contents of V2G service instruments are summarized in Table 1 according to the different deploying environments.
1) Charging price strategies. The GSO sets the charging price tactics to influence charging behaviors of EV owners and to reshape the charging load.

2) DSM service. The GSO gains the authorization of EV owners to switch the charging load of EVs in an appointed period.

3) V2G ancillary service. The GSO has access to dispatch or to inject the power of EVs at the appointed time with the V2G ancillary service.

\subsection{Division of V2G service development phases}

By comparing the $\mathrm{V} 2 \mathrm{G}$ services in Table 1, we get to know that the realization of the three $\mathrm{V} 2 \mathrm{G}$ services depends on the penetration rate of EVs and the smart degree of the distribution grid. In this paper, we assume that the diffusion of EVs is a developing process with time. The market pervasiveness of EVs will motivate the GSO to update or add the facilities to tackle the impact of EV charging [45]. The ongoing implementation of the new intelligent devices not only allows the DSO to communicate with EV owners more conveniently (that will help to solve the information asymmetry between DSO and EV owners) but also makes the complicated management modes more viable [46]. According to the characteristics of the coevolution process, the whole developing process of V2G services could be divided into three different phases: phase 1 (preliminary phase), phase 2 (development phase), and phase 3 (followup phase).

1) In phase 1, EVs are in the preliminary stage, and the charging load accounts for a small proportion of the whole grid load.

2) In phase 2, the charging load is increased so much that the grid stability is endangered. The GSO has to take measures to deal with it. The features of phase 2 not only contain the sharp proliferation of EVs but also include the enhancement of the power grid intelligence and the raising of the renewable resources ratio in the distribution grid.

3) In phase 3, the electricity grid has evolved into the ideal state of the smart grid. The GSO has the adequate capacity in both technology and management to cope with EVs and other intermittent power sources.

\subsection{Comprehensive analysis of different phases}

Integrating the three kinds of V2G services and the three developing phases, their evolution relations can be obtained, as shown in Fig. 2. On the graph, there are oneto-one correspondences between circular areas and the three V2G services. The circular areas show the potential 
Table 1 V2G services comparison

\begin{tabular}{|c|c|c|c|c|c|}
\hline Instruments & Power flow & Invested cost & Operating cost & Grid benefit & $\begin{array}{l}\text { Comparative } \\
\text { advantages }\end{array}$ \\
\hline $\begin{array}{l}\text { Charging } \\
\text { price } \\
\text { strategies }\end{array}$ & $\begin{array}{c}\text { Unidirectional } \\
\text { power flow }\end{array}$ & No additional invested cost & No additional operating cost & $\begin{array}{l}\text { Reshape the charging } \\
\text { load of EV as GSO } \\
\text { expects }\end{array}$ & $\begin{array}{l}\text { Easy } \\
\text { implementation; } \\
\text { little asset risk }\end{array}$ \\
\hline $\begin{array}{l}\text { DSM } \\
\text { service } \\
\text { contract }\end{array}$ & $\begin{array}{l}\text { Unidirectional } \\
\text { power flow }\end{array}$ & $\begin{array}{l}\text { Cost of adding starting- } \\
\text { stopping controlling } \\
\text { electronics in charger }\end{array}$ & $\begin{array}{l}\text { EV owners' opportunity cost } \\
\text { of losing control to their } \\
\text { vehicles }\end{array}$ & $\begin{array}{l}\text { Provide DSM services: } \\
\text { alleviating } \\
\text { congestion of } \\
\text { distribution } \\
\text { network; absorbing } \\
\text { extra renewable } \\
\text { source }\end{array}$ & $\begin{array}{l}\text { Easy control; small } \\
\text { asset risk }\end{array}$ \\
\hline $\begin{array}{l}\text { V2G } \\
\text { ancillary } \\
\text { service } \\
\text { option }\end{array}$ & $\begin{array}{l}\text { Bidirectional } \\
\text { power flow }\end{array}$ & $\begin{array}{l}\text { Cost of upgrading distribution } \\
\text { grid and EV chargers; cost of } \\
\text { some smart component, e.g. } \\
\text { interactive interface and } \\
\text { real-time telemetry on EV }\end{array}$ & $\begin{array}{l}\text { EV owners' opportunity cost } \\
\text { of losing control to their } \\
\text { vehicles; degradation cost } \\
\text { of battery because of } \\
\text { repeated cycling; } \\
\text { opportunity cost of losing } \\
\text { driving freedom when } \\
\text { executing V2G service }\end{array}$ & $\begin{array}{l}\text { Supply ancillary } \\
\text { services: keeping } \\
\text { frequency and } \\
\text { voltage deviations } \\
\text { within } \\
\text { acceptable ranges }\end{array}$ & $\begin{array}{l}\text { Higher controlling } \\
\text { capacity; higher } \\
\text { flexibility }\end{array}$ \\
\hline
\end{tabular}

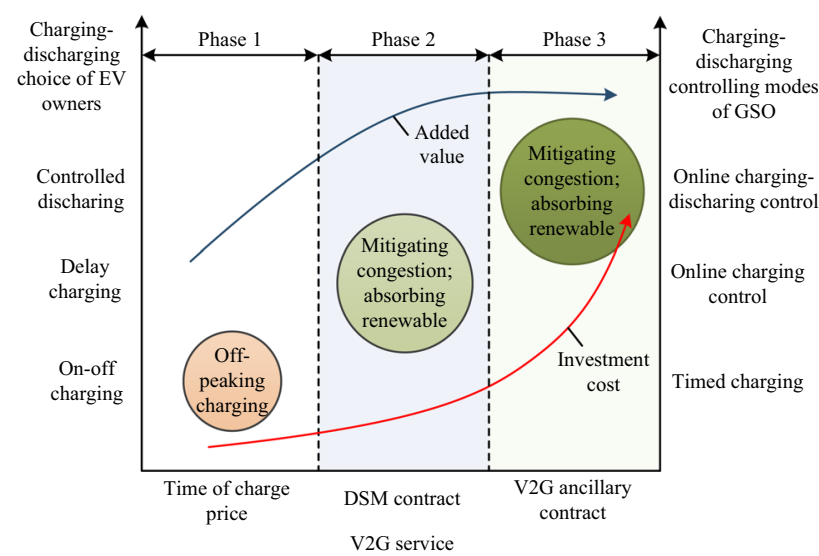

Fig. 2 Characteristics of different phases

benefit of the DSO. As shown in Fig. 2, the corresponding circles become bigger and bigger, because the potential benefit of the DSO got from V2G services, will be larger at the higher phase as the charging-discharging controlling ability of the DSO to EVs become more and more strong. The two curves around circular areas are to show the added value and extra investment cost in the process of realizing V2G services.

Although much research has justified the effectiveness of $\mathrm{V} 2 \mathrm{G}$ services, some potential risks cannot be avoided, such as the investment risk of advanced devices and the implementation risk of V2G services, since either GSO or EV owners, who expect to get the benefit of V2G services, must invest beforehand, when the future effectiveness is uncertain [47]. The risk factors will increase phase by phase. For instance, when the price strategies are introduced by the GSO, the executive risk (e.g. new charging load peak) might exist. To cope with the risk, advanced equipment will need to be invested in to reduce the uncertainties which stem from the contradictions among participators (illustrated in Section 2.2). This could be such things as adding a monitor sensor or communication device to reduce the risk of information asymmetry between suppliers (EV owners) and demander (DSO or V2G service aggregators). However, this will increase the additional investment risk of the DSO or V2G service aggregators and even lead to cyber risk. Because of the above dilemma, the marginal increment of added value of V2G services becomes smaller and smaller.

\section{Management formulation for V2G services}

In Section 3, we find that the development of $\mathrm{V} 2 \mathrm{G}$ services follows an evolutionary process. Along with this process, the corresponding management formulations will also change.

\subsection{Management architecture of different phases}

Many researchers have discussed the issues of $\mathrm{V} 2 \mathrm{G}$ services, based on three management architectures (centralized architecture, hierarchical architecture, and decentralized architecture) as shown in Fig. 3. The three architectures conform to the requirements of deploying the V2G services in different phases. 


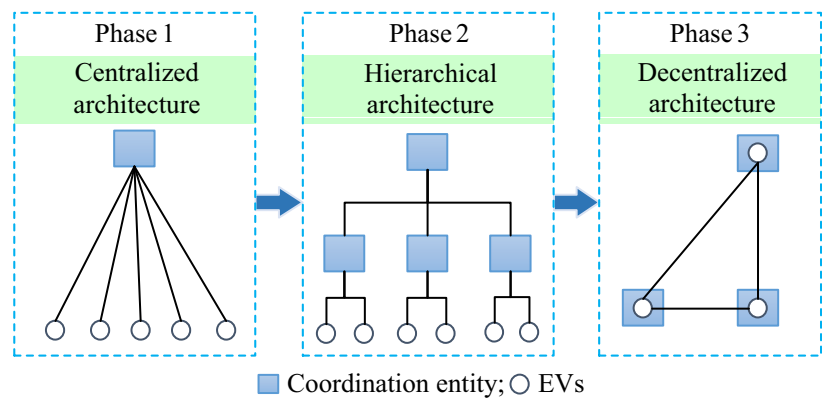

Fig. 3 Management architecture of different phases

\subsubsection{Centralized architecture of phase 1}

The centralized architecture is the current architecture of the distribution power grid, in which the GSO is responsible for ensuring the safe and reliable operation of the power grid. The characteristic of this architecture is the high controlling capacity of the GSO. The GSO communicates with the power companies in a timely fashion and controls the generators online according to the real-time operating situations of the electric power grid. This mode depends mainly on the stable cooperation relations between the GSO and power generation enterprises. However, this architecture lacks flexibility and leads to high cost, because some special generators, like reserve generators and ancillary facilities, must be added to deal with some uncommon situations, i.e. peak load and voltage drop. Extra investments are usually deemed as inefficient by some researchers. In this environment, the development of EVs at the preliminary stage may be beneficial to the whole power system, because the charging load of EVs could improve the utilization rate of the grid assets and increase the power sale revenue of the DSO [41]. Nonetheless, the advantage would disappear when the power consumption grows with the continuing penetration of EVs.

\subsubsection{Hierarchical architecture of phase 2}

The hierarchical V2G service architecture is a mixture of centralized architecture and decentralized architecture. The GSO chooses this architecture as a compromise way to tackle both the increasingly unstable load and intermittent power sources because the GSO will pay a huge cost to cope with the above problems if keeping the centralized control architecture of phase 1 . Moreover, in phase 2, the operating environment of the power grid is not so intelligent that the GSO could get accurate information about the V2G service trading inclination of EV owners, let alone having the capability to control them automatically. Therefore it is best to aggregate EVs and have them managed by an intermediary agent (usually called aggregator) who could coordinate EV owners to join in V2G services and invest in the related facilities. This way could efficiently decrease the management and investment pressure on the GSO and transfer the responsibility of conducting the charging of EVs to aggregators, in which the GSO just needs to manage a limited number of aggregators instead of large numbers of EV owners [48].

\subsubsection{Decentralized architecture of phase 3}

Although the hierarchical architecture seems applicable to the future management structure of the smart grid, there is a scenario where the decentralized management architecture would be more promising with the progress of advanced technologies [49]. In virtue of intelligent technologies like big data and cloud computing, the GSO could gather all the required information and control all devices [50], with the permission of EV owners. However, in this phase, the distribution power grid would be subdivided into many micro-grids to exploit the potential benefit adequately, i.e. synergizing charging-discharging of EVs and renewable power sources. The aggregators would evolve to the operators of the micro-grids [51], who bidirectionally transact with the GSO for both electricity and ancillary services.

\subsection{Management relations of different phases}

With the changes of physical architectures of the distribution power system, its management relations will make corresponding adjustments. The following contents of this section are to outline those adjustments.

\subsubsection{Management relations of phase 1}

The management relations of phase 1 in distribution power systems are constituted with two participants: the GSO and power consumers. The EV owner is not a special power consumer due to the small influence on charging load. In the management architecture of phase 1, the objectives of the GSO are to balance the power and to resolve some operational problems such as voltage drop, frequency deviation, ect. The GSO could remodel the power consumption choices of EV owners through price tactics in which the GSO is a price maker. As Fig. 4 illustrates, in phase 1, the charging loads of EVs and the electricity from renewable generation are so little that the GSO hardly deals with them in any special manner, though they will play important roles in the future power system. Even when the number of EVs is no longer negligible, the price strategy still is one of the economic measures for the GSO to mitigate the negative influence of EV charging with the help of smart meters. The optimal expectation of phase 1 is that EV owners could change their charging 


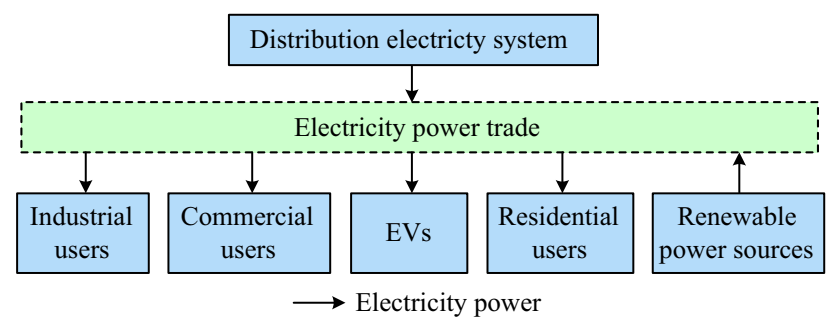

Fig. 4 Management relations of phase 1

habits influenced by the charging price strategies which are set by the GSO.

\subsubsection{Management relations of phase 2}

The smart equipment application in phase 2, especially the usage of two-way communication devices, widens the scope of V2G service options of the GSO. The demand response services of EVs could be utilized. EV owners would sign DSM contracts beforehand, promising to obey the order of changing their charging schedule. This vision is fascinating, but persuading EV owners is a burdensome task that the GSO might not be able to afford. So it is the sensible choice to solve this problem through management innovation. Embedding aggregators between the GSO and EV owners is accepted by the majority of scholars [52, 53], as demonstrated in Fig. 5.

The aggregators are independent organizations who investigate the potential benefit [54], aggregate the separate EVs, and invest in facilities for supporting control [55]. The revenue of aggregators comes from the arbitrage in bargaining with the GSO. Aggregators promise to follow the orders of the GSO at the appointed time. The GSO shares the benefit to aggregators in return, according to whether aggregators follow their promises well. So aggregators have strong motivations to coordinate EV owners to make their charging behavior forecastable or controllable so as to enhance the quality of $\mathrm{V} 2 \mathrm{G}$ services. DSM contracts would be signed between the aggregators and EV owners. When the DSM contracts are executed, the separate EVs are aggregated to form a so-called active distribution system (ADS).

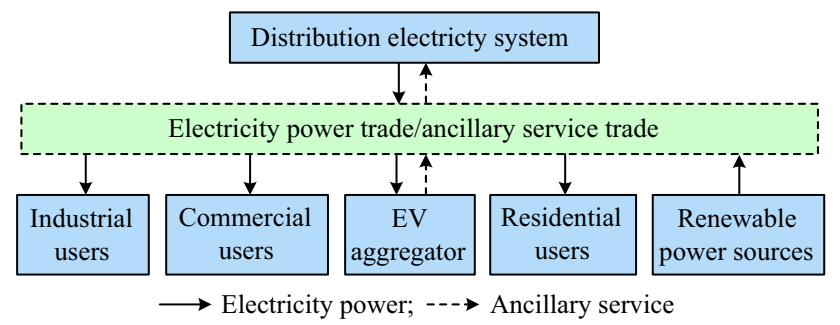

Fig. 5 Trade model of aggregator in phase 2

\subsubsection{Management relations of phase 3}

The main characteristics of the power grid of phase 3 are intelligent and automatic. In this phase, the cost of both communicating and controlling EVs would be lower than in other phases. The smart devices and sensors have penetrated in every corner of the whole power system. The interactions among all agents become very convenient. Additionally, the EV owners would be familiar with the V2G services [56] and more stakeholders take part in V2G services or other power service programs actively due to lower investment risk. All these beneficial conditions support the realization of a V2G ancillary service. In this phase, the aggregators act as microgrid operators. The controlling systems of the GSO could integrate with the service management systems of aggregators, while the service transactions are conducted [57] the physical structure shown in Fig. 6.

In phase 3 there will be a community-based service market, in which all the aggregators or power service providers compete with each other and struggle to trade ancillary service with the GSO, as shown in Fig. 7. Reference [58] proposed a similar hierarchical structure for the electricity market to facilitate the coordination of energy markets in distribution networks. The GSO selects coordinators to cooperate based on the calculated outcome of a complicated algorithm to help with some advanced technologies, e.g. cloud computing, big data storage and

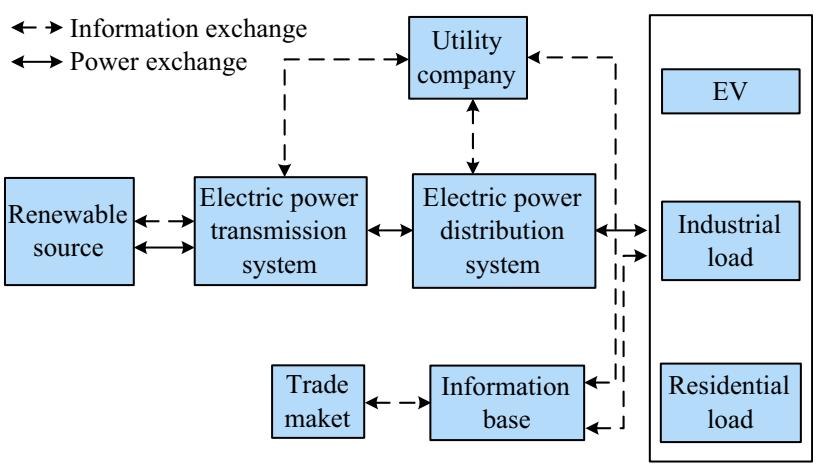

Fig. 6 Controlling environment of GSO

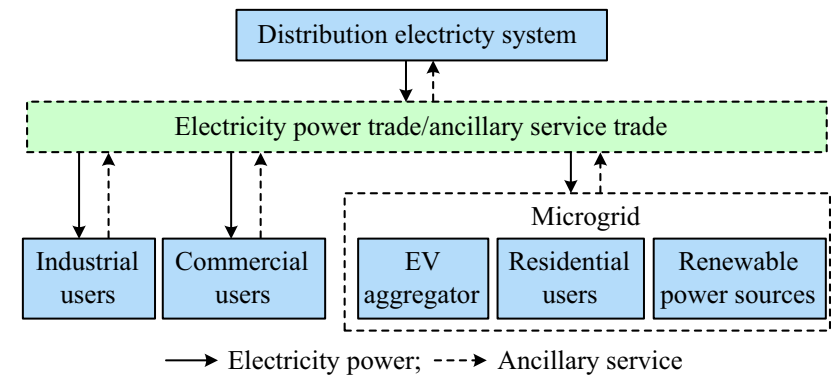

Fig. 7 Trade model of aggregator in phase 3 
Table 2 Management agents of distribution grid in different phases

\begin{tabular}{|c|c|c|c|}
\hline Phase & $\begin{array}{l}\text { Operator of } \\
\text { distribution grid }\end{array}$ & Duty & $\begin{array}{l}\text { Management } \\
\text { level }\end{array}$ \\
\hline 1 & GSO & Set charging price strategies to keep the operation of distribution grid safe, stable and economic & $\begin{array}{l}\text { Primary } \\
\text { control }\end{array}$ \\
\hline 2 & GSO & $\begin{array}{l}\text { Set charging price strategies, trade with aggregators in terms of V2G DSM services and keep the } \\
\text { operation of distribution grid safe, stable and economic }\end{array}$ & $\begin{array}{l}\text { Secondary } \\
\text { control }\end{array}$ \\
\hline 2 & Aggregators & $\begin{array}{l}\text { Supply charging power of EVs; design DSM contracts to control charging of EVs and pursue a } \\
\text { transaction with GSO to get profits; determine how and when each vehicle is to be charged, } \\
\text { thereby providing DSM service for GSO }\end{array}$ & $\begin{array}{l}\text { Secondary } \\
\text { control }\end{array}$ \\
\hline 3 & GSO & $\begin{array}{l}\text { Trade with aggregators in terms of electricity and V2G ancillary services to keep operation of } \\
\text { distribution grid safe, stable and economic }\end{array}$ & $\begin{array}{l}\text { Tertiary } \\
\text { control }\end{array}$ \\
\hline 3 & Aggregators & $\begin{array}{l}\text { Get profit through managing charging-discharging of EV through synergizing renewable power } \\
\text { source in microgrid }\end{array}$ & $\begin{array}{l}\text { Tertiary } \\
\text { control }\end{array}$ \\
\hline
\end{tabular}

analytic technology as well as remote control technology [59]. In addition, the GSO would interact with generation companies to import/export energy to/from the distribution grid electricity markets from/to the wholesale electricity market [60]. Hence the optimization process of the GSO's controlling algorithm is composed of tri-level optimization problems. These could be solved by developing sensitivity functions for market participants' payoff with respect to their bidding strategies [61], while taking into account the uncertainties of the wholesale electricity market [25].

\subsection{Management measures of different phases}

Through the analysis of the above part of this article, the development logic of V2G services is outlined, in which the management architectures and the management relations evolve in each phase. The controlling power of the GSO to EVs' charging-discharging will also be strengthened phase by phase, with the help of both the advanced technologies and the relevant management models. Figures 4, 5 and 7 showcase this process; Table 2 illustrates the duty change of stakeholders in different phases. Because of these changes, V2G services' management measures will change too. Combining Figs. 3, 4, 5, 7 and Table 2, the management measures of each phase could be summarized as follows.

\subsubsection{Management measures of phase 1}

In phase 1, the price strategies, like time-of-use (TOU) price strategy, are employed by the GSO (price-maker) usually to influence the charging time choice of EV owners (price-takers) indirectly, as illustrated in Fig. 8 [62]. The price strategy decisions could be made according to the following function:

$\min C\left(P_{\text {char }}\right)=C_{\mathrm{DSO}}+C_{\mathrm{EV}}$

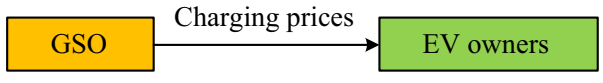

Fig. 8 Management measures of phase 1

where $C_{\mathrm{DSO}}$ denotes the operational cost of the DSO; $C_{\mathrm{EV}}$ is the charging cost of EVs; $P_{\text {char }}$ is the charging prices the GSO sets. When the aggregated cost reaches minimization, the proposed price strategies are optimal. Overall the ideal situations happen while the charging load of EVs is shifted to the valley load of the distribution grid without causing a new load peak.

The iterative price discovery method is a commonly used way to decide optimal supporting prices [63]. Such a framework assumes that the DSO sends real-time prices to EV owners after receiving charging demands, while EV owners adjust their charging patterns in response to the prices,. This interaction keeps repeating until arriving at an equilibrium. A shortcoming of this approach, however, is that equilibria may be unstable or difficult to compute [64], without any guarantee of convergence. Reference [65] overcame this issue by adding a regularization term, which penalizes differences between each PEV's charging profile and the population average, to the grid operators' objective functions.

\subsubsection{Management measures of phase 2}

When aggregators emerge in phase 2 , they could assist the GSO in improving the operational state of the distribution power grid through signing DSM service contracts with the GSO and EV owners respectively. The whole goal of phase 2 is shown in Fig. 9 [27].

In this phase, the objective of the GSO is still to minimize the total cost of system operation, including the operational cost $C_{\mathrm{DSO}}$ and the purchase cost of $\mathrm{V} 2 \mathrm{G}$ 


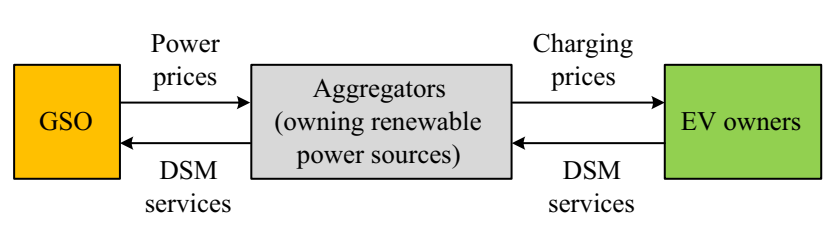

Fig. 9 Management measures of phase 2

services $C_{\mathrm{DSM}}$. The trading decisions of the aggregator are made after calculating the profit synthetically based on the DSM services' revenues $R_{\mathrm{DSM}}$ from the GSO, the expenditure $C_{\mathrm{DSM}}^{\mathrm{EV}}$ for EVs' DSM services and the power cost $C_{\text {power }}$ from the GSO. EV owners pursue the balance of DSM revenue $R_{\mathrm{DSM}}^{\mathrm{EV}}$ and driving freedom cost $C_{\text {freedom }}$ as well as charging power cost $C_{\text {char }}$. The decision functions of all participants are:

$$
\begin{gathered}
\min C\left(P_{\text {power }}^{\text {aggre }}, P_{\mathrm{DSM}}^{\text {aggre }}\right)=C_{\mathrm{DSO}}+C_{\mathrm{DSM}} \\
\max F_{\mathrm{PRO}}\left(P_{\text {char }}, P_{\mathrm{DSM}}^{\text {aggre }}, P_{\mathrm{DSM}}^{\mathrm{EV}}\right)= \\
R_{\text {power }}+R_{\mathrm{DSM}}-C_{\text {power }}-C_{\mathrm{DSM}}^{\mathrm{EV}} \\
\max U\left(P_{\mathrm{DSM}}^{\mathrm{EV}}\right)=R_{\mathrm{DSM}}^{\mathrm{EV}}-C_{\text {char }}-C_{\text {freedom }}
\end{gathered}
$$

When the (2)-(4) are satisfied, the management measures of phase 3 could achieve the optimal. Equation (2) is the decision function of the GSO, whose management measure variables are the power price $P_{\text {power }}^{\text {aggre }}$ and the DSM service price $P_{\mathrm{DSM}}^{\text {aggre }}$. Depending on the strategy set $\left(P_{\text {power }}^{\text {aggre }}, P_{\mathrm{DSM}}^{\text {aggre }}\right)$, the goal of the DSO could be reached, through influencing the strategy setting of aggregators, because $P_{\text {power }}^{\text {aggre }}$ and $P_{\mathrm{DSM}}^{\text {aggre }}$ determine the aggregators' cost of purchasing electricity and the revenue of the DSM service trade directly. Reference [66] described a heuristic algorithm for controlling the EV charging in response to a TOU price in a regulated electricity market. Reference [67] studied the reaction of aggregators when the GSO sends price-based signals to aggregators. The outcome proved that the price/quantitybased mechanism could yield a socially optimal solution. Equation (3) is the decision function of the aggregator, who decides its strategy set $\left(P_{\text {char }}, P_{\mathrm{DSM}}^{\text {aggre }}, P_{\mathrm{DSM}}^{\mathrm{EV}}\right)$ aiming to maximize profit, mainly depending on the revenue of selling charging power $R_{\text {power }}$ and the revenue of trading DSM services $P_{\mathrm{DSM}}$. $P_{\text {char }}$ is the charging price to EVs; $P_{\mathrm{DSM}}^{\mathrm{EV}}$ is the price in the DSM services contracts between aggregators and EV owners. EV owners choose whether to provide DSM services, based on the principle of utility maximization, after weighing the relation between their revenue and cost (containing the charging cost and the limited-driving freedom cost).

Currently, the relevant research usually neglects how to reinforce the transaction relationship between the GSO and

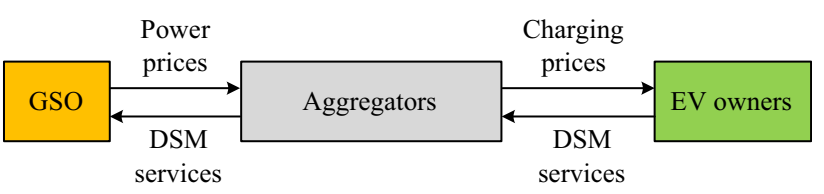

Fig. 10 Management measures of phase 3

aggregators and how to enhance aggregators' enthusiasm to take part in V2G DSM service. In [68], an optimal contract size of V2G service was analyzed, considering several possible types of penalty. Reference [69] presented a twostage stochastic optimization approach for aggregators to reduce their energy cost. Furthermore, to make the concept of V2G DSM services attractive to EV owners, aggregators have to scrupulously design their contracts, which are characterized by contract parameters such as plug-in duration or guaranteed driving range. Reference [70] strongly emphasised the parameters of influencing EV owners.

\subsubsection{Management measures of phase 3}

There is a crucial difference between phase 2 and phase 3. Phase 2 belongs to the hierarchical management structure, in which the GSO still takes control of the whole distribution grid as in phase 1 , but in phase 3 , the duty of the aggregator evolves to manage the community-level micro-grid, and will compete with other aggregators in a district service market, as shown in Fig. 10 [70]. The GSO sells electricity to aggregators and buys the V2G ancillary service to keep the distribution grid system in an optimal state.

The decision function of the GSO is (5); its strategy set is $\left(P_{\text {power }}^{\text {aggre }}, P_{\text {ancill }}^{\text {aggre }}\right)$, setting the power price $P_{\text {power }}^{\text {aggre and }}$ selecting the best transaction price $P_{\text {ancill }}^{\text {aggre }}$ of $2 \mathrm{G}$ ancillary service in the district service market. The objective of the GSO is still to minimize the its total cost, including the operational cost $C_{\mathrm{DSO}}$ and the purchase cost of $\mathrm{V} 2 \mathrm{G}$ ancillary service $C_{\text {ancill }}$. In the district service market, the GSO would lead leader-followers games. For example, it could release their demand information and the price cap that is based on both the demand forecasting of an ancillary service and market clearing price. The price cap not only encourages the aggregators to bid at a lower price [71] but also decreases the complication of the trading game [72]. A comprehensive cost-minimizing adaptive bidding strategy is suggested based on both the potential risk according to the aggregators' historic performance and their bidding prices [5].

$$
\min C\left(P_{\text {power }}^{\text {aggre }}, P_{\text {ancill }}^{\text {aggre }}\right)=C_{\mathrm{DSO}}+C_{\text {ancill }}
$$




$$
\begin{gathered}
\max F_{\mathrm{PRO}}\left(P_{\text {char }}, P_{\text {ancill }}^{\text {aggre }}, P_{\text {ancill }}^{\mathrm{EV}}\right)= \\
R_{\text {power }}+R_{\text {ancill }}-C_{\text {power }}-C_{\text {ancill }}^{\mathrm{EV}} \\
\max U\left(P_{\text {ancill }}^{\mathrm{EV}}\right)=R_{\text {ancill }}^{\mathrm{EV}}-C_{\text {char }}-C_{\text {freedom }}
\end{gathered}
$$

The aggregator pursues maximization of its profit as shown in (6). Its strategy set is $\left(P_{\text {char }}, P_{\text {ancill }}^{\text {aggre }}, P_{\text {ancill }}^{\mathrm{EV}}\right)$, through which aggregator can get the revenue of selling charging power $R_{\text {power }}$ and the revenue of trading $\mathrm{V} 2 \mathrm{G}$ ancillary services $R_{\text {ancill }}$. The trading decisions of the aggregator are made after calculating the profit synthetically based on the DSM services' revenues $R_{\text {power }}+R_{\text {ancill }}$ from the GSO, the expenditure $C_{\mathrm{ancill}}^{\mathrm{EV}}$ for EVs' ancillary services and the power cost $C_{\text {power }}$ from the GSO. In special situations, the aggregator's electricity for EV charging may not be all from the GSO, e.g. when it owns renewable generators [38]. Many algorithms have been developed for supporting the participation of EV aggregators in the electrical energy and the ancillary market. Monte Carlo simulation (MCS) was used in [73] to evaluate optimal bidding strategies in electricity reserve markets. Reference [74] developed a linear programming model for defining the optimal charging plan for EV fleets with V2G by minimizing costs (electricity and battery wear) for a fleet operator in the day-ahead electrical energy market.

On the other hand, EV owners will decide to take part in the V2G ancillary services if the objective of (7) could be achieved. In (7), $R_{\text {ancill }}^{\mathrm{EV}}$ is the $\mathrm{V} 2 \mathrm{G}$ ancillary services revenue EV owners earn.

In the trading process, potential uncertainties should be considered, like forecast errors in EV fleet characteristics, hourly loads, and renewable energy as well as random outages of generating units and transmission lines. So the DSO should elaborate a suitable trading plan in the deployment-ahead horizon, in order to program all factors accounting for economic burdens, environmental impact and reliability issues [75-77]. During the process of designing the trading plans, possible deviations of forecasts with proper probability distribution functions [78-80], procedures based on the generation of different scenarios with relevant probability [81-84], and methodologies based on deterministic data [49, 85-88] should be taken into account. In addition, the penalty mechanism should be constructed to hedge against the aggregators' failure to execute the V2G ancillary service [89]. The DSO should impose penalties on the aggregators when and if they fail to commit the contracted V2G ancillary service so that the aggregators are stimulated to estimate (predict) the V2G service capacity as accurately as possible rather than just submitting an exaggerated over-capacity [90].

\section{Discussion}

The above content of this paper mainly discusses the development logic of $\mathrm{V} 2 \mathrm{G}$ services and their management formulation from a macro-evolving perspective, in which the participants and their reactions are presented. However, the management problems of every participant themselves are not analyzed. For example, how to allocate the resource to maximize the profit of aggregators and how to incentivize EV owners to join the V2G services and avoid their default, etc. These micro problems have been addressed in much previous research. In [91], the simultaneous allocation of EV charging stations and distributed renewable resources and its effect on system losses are investigated. In this work, the demand for vehicle charging has been modeled considering their mileage and the duration to fully charge. EV parking was also used as a vehicle aggregator and renewable resources were considered as stochastic generation resources. In [92], an allocation approach is proposed for EV parking lots considering the welfare of EV owners.

The other works enlighten us that government may be best placed to take part in the V2G services trade if the whole optimization is expected to be achieved and the trade discrimination (e.g. trading prices discrimination) could be avoided. In practice, government is the core impetus of propelling $\mathrm{V} 2 \mathrm{G}$ services, especially in the initial stage. For example, through "Los Angeles Air Force Base Vehicle to Grid Pilot Project" led by U.S. Air Force, the related technologies and the market mechanism have been verified; moreover, it also concluded that many policy hurdles (e.g. high regulatory barriers) must be removed. The other project is initiated by U.S. National Renewable Energy Laboratory, which aims to understand V2G services benefits, and to evaluate grid interoperability standards. In terms of Europe, the "SEEV4-City" project has been launched by 13 partners from 5 cities across Europe. The main aim of SEEV4-City is to develop the concept "Vehicle for Energy" services into sustainable (commercially and socially viable) business models to integrate EVs and renewable energy. In addition, other stakeholders also initiate their demonstration projects of $\mathrm{V} 2 \mathrm{G}$ services. Take "Parker" for example. This is sponsored by Nissan, NUVVE, Frederiksberg Forsyning, Mitsubishi Motors and other companies. The objective of this project is to validate electric vehicles as part of an operational vehicle fleet that can support the power grid by becoming a vertically integrated resource, providing seamless support (i.e. V2G) to the power grid both locally and systemwide. 


\section{Conclusion}

In general, the development of EVs is a dynamic and complicated process and needs to harmonize with the development of other factors. The relation with the power grid is one of the vital factors. To hedge against the negative influence of EV charging, some technological and management innovations should be implemented. So far, there is already a lot of work attempting to resolve the new challenge and the idea of V2G service is widely considered. Without doubt, this research has established the firm foundation for propelling the realization of V2G services. Nonetheless, little research describes the development process of V2G services from the holistic perspective. This impedes our ability to assess in depth the suitability of different relevant research. This current work analyzed the features of V2G services, sorted out the V2G services into three types, summarized their respective characteristics, and then made a full scheme in view of the coevolution relation between the grid upgrading and the developing of $\mathrm{EV}$, through a dynamic and evolving perspective. A physical trade structure and the corresponding management hierarchy, management relations as well as management measures were proposed. Some details of management were discussed. This paper provides a new perspective of V2G services development, answers the core question on how to realize the V2G vision in synergy with the development of EVs and the upgrade of the distribution grid, and offers advice on the future V2G management mechanism.

Acknowledgements This work was supported by the National Natural Science Foundation of China (No. 51507022), the Humanities and Social Sciences Projects of the Ministry of Education of China (No. 18YJC790137), the Science and Technology Research Program of Chongqing Education Commission (No. KJ1703067) and the Top Talent Plan of Chongqing Normal University (No. 020303070059).

Open Access This article is distributed under the terms of the Creative Commons Attribution 4.0 International License (http:// creativecommons.org/licenses/by/4.0/), which permits unrestricted use, distribution, and reproduction in any medium, provided you give appropriate credit to the original author(s) and the source, provide a link to the Creative Commons license, and indicate if changes were made.

\section{References}

[1] Kempton W, Tomić J (2005) Vehicle-to-grid power fundamentals: calculating capacity and net revenue. J Power Sour 144(1):268-279

[2] Wang Y, Sheikh O, Hu B et al (2014) Integration of V2H/V2G hybrid system for demand response in distribution network. In: Proceedings of IEEE international conference on smart grid communications, Venice, Italy, 3-6 November 2014, pp 812817
[3] Gaviano A, Weber K, Dirmeier C (2012) Challenges and integration of $\mathrm{PV}$ and wind energy facilities from a smart grid point of view. Energy Procedia 25:118-125

[4] Vayá MG, Andersson G (2016) Self-scheduling of plug-in electric vehicle aggregator to provide balancing services for wind power. IEEE Trans Sustain Energy 7(2):886-899

[5] Shi L, Zhang Q, Pu Y (2013) The reserve trading model considering V2G reverse. Energy 59(15):50-55

[6] Sortomme E, El-Sharkawi MA (2011) Optimal charging strategies for unidirectional vehicle-to-grid. IEEE Trans Smart Grid 2(1):131-138

[7] Hidrue MK, Parsons GR (2015) Is there a near-term market for vehicle-to-grid electric vehicles? Appl Energy 151:67-76

[8] Kempton W, Letendre SE (1997) Electric vehicles as a new power source for electric utilities. Transp Res D Transp Environ 2(3):157-175

[9] Bauer P, Zhou Y, Doppler J (2010) Charging of electric vehicles and impact on the grid. In: Proceedings of 13th international symposium mechatronika, Trencianske Teplice, 2-4 June 2010, pp 121-127

[10] Kristien CN, Edwin H, Driesen J (2010) The impact of charging plug-in hybrid electric vehicles on a residential distribution grid. IEEE Trans Power Syst 25(1):371-380

[11] Turitsyn K, Sinitsyn N, Backhaus S et al (2010) Robust broadcast communication control of electric vehicle charging. In: Proceedings of IEEE international conference on smart grid communications, Gaithersburg, USA, 4-6 October 2010, pp 203-207

[12] Sortomme E, Hindi MM, Macpherson SDJ et al (2011) Coordinated charging of plug-in hybrid electric vehicles to minimize distribution system losses. IEEE Trans Smart Grid 2(1):198-205

[13] Moradijoz M, Moghadam MP, Haghifam MR et al (2013) A multi-objective optimization problem for allocating parking lots in a distribution network. Int $\mathbf{J}$ Electr Power Energy Syst 46:115-122

[14] Denholm P, Short W (2006) An evaluation of utility system impacts and benefits of optimally dispatched plug-in hybrid electric vehicles. Technical report

[15] Vachirasricirikul S, Ngamroo I (2012) Robust controller design of micro turbine and electrolyzer for frequency stabilization in a micro grid system with plug-in hybrid electric vehicles. Int $\mathbf{J}$ Electr Power Energy Syst 43(1):804-811

[16] Druitt J, Früh WG (2012) Simulation of demand management and grid balancing with electric vehicles. J Power Sour 216(15):104-116

[17] Masoum AS, Deilami S, Moses PS et al (2011) Smart load management of plug-in electric vehicles in distribution and residential networks with charging stations for peak shaving and loss minimization considering voltage regulation. IET Gener Transm Distrib 5(8):877-888

[18] Mao T, Lau W, Shum C et al (2018) A regulation policy of EV discharging price for demand scheduling. IEEE Trans Power Syst 33(2):1275-1288

[19] Mozafar MR, Amini MH, Moradi MH (2018) Innovative appraisement of smart grid operation considering large-scale integration of electric vehicles enabling V2G and G2V systems. Electr Power Syst Res 154:245-256

[20] Ahmadian A, Sedghi M, Mohammadi-Ivatloo B et al (2018) Cost-benefit analysis of $\mathrm{V} 2 \mathrm{G}$ implementation in distribution networks considering PEVs battery degradation. IEEE Trans Sustain Energy 9(2):961-970

[21] Guille C, Gross G (2009) A conceptual framework for the vehicle-to-grid (V2G) implementation. Energy Policy 37(11):4379-4390 
[22] Richardson DB (2013) Encouraging vehicle-to-grid (V2G) participation through premium tariff rates. J Power Sour 243:219-224

[23] Shi L, Liu Z, Pu Y et al (2016) A reserve dispatch paradigm considering vehicle-to-grid reserve. Electr Power Compon Syst 44(5):471-479

[24] Brooks A, Lu A, Reicher D et al (2010) Demand dispatch. IEEE Power Energ Mag 8(3):20-29

[25] Xu Z, Hu Z, Song Y et al (2017) Risk-averse optimal bidding strategy for demand-side resource aggregators in day-ahead electricity markets under uncertainty. IEEE Trans Smart Grid 8(1):96-105

[26] Sheikhi A, Bahrami S, Ranjbar AM et al (2013) Strategic charging method for plugged in hybrid electric vehicles in smart grids: a game theoretic approach. Electr Power Energy Syst 53:499-506

[27] Bahrami S, Wong VWS (2015) A potential game framework for charging PHEVs in smart grid. In: Proceedings of IEEE Pacific Rim conference on communications, computers and signal processing, Victoria, Canada, 24-26 August 2015, pp 28-33

[28] Bahrami S, Parniani M (2014) Game theoretic based charging strategy for plug-in hybrid electric vehicles. IEEE Trans Smart Grid 5(5):2368-2375

[29] Hadley SW, Tsvetkova AA (2009) Potential impacts of plug-in hybrid electric vehicles on regional power generation. Electr J 22(10):56-68

[30] Liu R, Dow L, Liu E (2011) A survey of PEV impacts on electric utilities. In: Proceedings of the IEEE PES innovative smart grid technologies, Anaheim, USA, 17-19 January 2011, 8 $\mathrm{pp}$

[31] White CD, Zhang KM (2011) Using vehicle-to-grid technology for frequency regulation and peak-load reduction. J Power Sour 196(8):3972-3980

[32] Diao W, Xue N, Bhattacharjee V et al (2018) Active battery cell equalization based on residual available energy maximization. Appl Energy 210(15):690-698

[33] Gao S, Chau KT, Chan CC et al (2011) Optimal control framework and scheme for integrating plug-in hybrid electric vehicles into grid. J Asian Electr Veh 9(1):1473-1481

[34] Oxley JE (1997) Appropriability hazards and governance in strategic alliances: a transaction cost approach. J Law Econ Org 13(2):387-409

[35] Williamson OE (1991) Comparative economic organization: the analysis of discrete structural alternatives. Adm Sci Q 36(2):269-296

[36] Tushar W, Yuen C, Smith DB et al (2017) Price discrimination for energy trading in smart grid: a game theoretic approach. IEEE Trans Smart Grid 8(4):1790-1801

[37] Shafie-Khah M, Moghaddam MP, Sheikh-El-Eslami MK et al (2012) Modeling of interactions between market regulations and behavior of plug-in electric vehicle aggregators in a virtual power market environment. Energy 40(1):139-150

[38] Hongcai Z, Zechun H, Munsing E et al (2018) Data-driven chance-constrained regulation capacity offering for distributed energy resources. IEEE Trans Smart Grid. https://doi.org/10. 1109/TSG.2018.2809046

[39] Tortos JQ, Ochoa LF, Alnaser SW et al (2016) Control of EV charging points for thermal and voltage management pf LV networks. IEEE Trans Power Syst 31(4):3028-3039

[40] Manz D, Walling R, Miller N et al (2014) The grid of the future. IEEE Power Energ Mag 7(2):26-36

[41] Parsons GR, Hidrue MK, Kempton W et al (2014) Willingness to pay for vehicle-to-grid (V2G) electric vehicles and their contract terms. Energy Econ 42:313-324

[42] Geske J, Schumann D (2018) Willing to participate in vehicleto-grid (V2G)? Why not! Energy Policy 120:392-401
[43] Stephen H, Timothy JF (2014) Values in the smart grid: the coevolving political economy of smart distribution. Energy Policy 74:600-609

[44] Martin C, Starace F, Tricoire JP (2017) The future of electricity new technologies transforming the grid edge. World economic forum report

[45] Farhangi $H(2010)$ The path of the smart grid. IEEE Power Energ Mag 8(1):18-28

[46] Shaaban MF, Atwa YM, El-Saadany EF (2013) PEVs modeling and impacts mitigation in distribution networks. IEEE Trans Power Syst 28(2):1122-1131

[47] Yu JJQ, Lin J, Lam AYS et al (2015) Coordinated electric vehicle charging control with aggregator power trading and indirect load control. In: Proceedings of IEEE international conference on smart grid communications, Miami, USA, 2-5 November 2015, 7 pp

[48] Guerrero JM, Chandokar M, Lee TL et al (2013) Advanced control architectures for intelligent microgrids-part I: decentralized and hierarchical control. IEEE Trans Ind Electron 60(4):1254-1262

[49] Gaithersburg MD (2010) NIST framework and roadmap for smart grid interoperability standards. Technical report

[50] Aluisio B, Conserva A, Dicorato M et al (2017) Optimal operation planning of $\mathrm{V} 2 \mathrm{G}$-equipped microgrid in the presence of EV aggregator. Electr Power Syst Res 152:295-305

[51] Gkatzikis L, Koutsopoulos I, Salonidis T (2013) The role of aggregators in smart grid demand response markets. IEEE J Sel Areas Commun 31(7):1247-1257

[52] Zugno M, Morales JM, Pinson P et al (2013) A bilevel model for electricity retailers' participation in a demand response market environment. Energy Econ 36:182-197

[53] Zhang H, Hu Z, Xu Z et al (2017) Evaluation of achievable vehicle-to-grid capacity using aggregate PEV model. IEEE Trans Power Syst 32(1):784-794

[54] Rahimi F, Ipakchi A (2016) Using a transactive energy framework. IEEE Electrif Mag 4(4):23-29

[55] Rogers EM (2003) Diffusion of innovations. Free Press, New York

[56] Yong JY, Ramachandaramurthy VK, Tan KM et al (2015) A review on the state-of-the-art technologies of electric vehicle, its impacts and prospects. Renew Sustain Energy Rev 49:365-385

[57] Parhizi S, Khodaei A (2018) Market-based vs. price-based microgrid optimal scheduling. IEEE Trans Smart Grid 9(2):615-623

[58] Manshadi SD, Khodayar ME (2016) A hierarchical electricity market structure for the smart grid paradigm. IEEE Trans Smart Grid 7(4):1866-1875

[59] Doostizadeh M, Ghasemi H (2013) Day-ahead scheduling of an active distribution network considering energy and reserve markets. Int Trans Electr Energy Syst 23(7):930-945

[60] Zhang L, Li Z, Wu C (2014) Randomized auction design for electricity markets between grids and microgrids. In: Proceedings of ACM international conference on measurement and modeling of computer systems, New York, USA, 16-20 June 2014, pp 99-110

[61] Sundström O, Binding C (2012) Flexible charging optimization for electric vehicles considering distribution grid constraints. IEEE Trans Smart Grid 3(1):26-37

[62] Gan L, Topcu U, Low S (2013) Optimal decentralized protocol for electric vehicle charging. IEEE Trans Power Syst 28(2):940-951

[63] Daskalakis C, Goldberg PW, Papadimitriou CH (2009) The complexity of computing a Nash equilibrium. Commun ACM 52(2):89-97

[64] Ma Z, Callaway D, Hiskens I (2012) Optimal charging control for plug-in electric vehicles. Springer, New York, pp 259-273 
[65] Cao Y, Tang S, Li C et al (2012) An optimized EV charging model considering TOU price and SOC curve. IEEE Trans Smart Grid 3(1):388-393

[66] Xi X, Sioshansi R (2014) Using price-based signals to control plug-in electric vehicle fleet charging. IEEE Trans Smart Grid 5(3): 1451-1464

[67] Jang S, Han S, Han SH et al (2010) Optimal decision on contract size for $\mathrm{V} 2 \mathrm{G}$ aggregator regarding frequency regulation. In: Proceedings of international conference on optimization of electrical and electronic equipment, Basov, Romania, 20-22 May 2010, pp 54-62

[68] Vagropoulos SI, Bakirtzis AG (2013) Optimal bidding strategy for electric vehicle aggregators in electricity markets. IEEE Trans Power Syst 28(4):4031-4041

[69] Broneske G, Wozabal D (2017) How do contract parameters influence the economics of vehicle-to-grid? Manuf Serv Oper Manag 19(1):150-164

[70] Baringo L, Amaro RS (2017) A stochastic robust optimization approach for the bidding strategy of an electric vehicle aggregator. Electr Power Syst Res 146:362-370

[71] Rassaei F, Soh WS, Chua KC (2016) Distributed scalable autonomous market-based demand response via residential plug-in electric vehicles in smart grids. IEEE Trans Smart Grid 9(4):3281-3290

[72] Zhao F, Luh PB, Yan JH et al (2010) Bid cost minimization versus payment cost minimization: a game theoretic study of electricity auctions. IEEE Trans Power Syst 25(1):181-194

[73] Sandels C, Franke U, Ingvar N et al (2010) Vehicle to gridMonte Carlo simulations for optimal aggregator strategies. In: Proceedings of international conference on power system technology, Hangzhou, China, 24-28 October 2010, 8 pp

[74] Kristoffersen TK, Capion K, Meibom P (2011) Optimal charging of electric drive vehicles in a market environment. Appl Energy 88(5):1940-1948

[75] Le TN, Al-Rubaye S, Liang H et al (2015) Dynamic charging and discharging for electric vehicles in microgrids. In: IEEE international conference on communication workshop, London, UK, 8-12 June 2015, pp 2018-2022

[76] Mao M, Jin P, Hatziargyriou ND et al (2014) Multiagent-based hybrid energy management system for microgrids. IEEE Trans Sustain Energy 5(3):938-946

[77] Deckmyn C, de Vyver JV, Vandoorn TL et al (2017) Day-ahead unit commitment model for microgrids. IET Gener Transm Distrib 11(1):1-9

[78] Kamankesh H, Agelidis VG, Kavousi-Fard A (2016) Optimal scheduling of renewable microgrid considering plug-in hybrid electric vehicle charging demand. Energy 100:285-297

[79] Yang H, Pan H, Luo F et al (2017) Operational planning of electric vehicles for balancing wind power and load fluctuations in a microgrid. IEEE Trans Sustain Energy 8(2):592-604

[80] Anastasiadis AG, Konstantinopoulos S, Kondylis GP et al (2017) Electric vehicle charging in stochastic smart microgrid operation with fuel cell and RES units. Int J Hydrogen Energy 42(12):8242-8254

[81] Kou P, Liang D, Gao L et al (2016) Stochastic coordination of plug-in electric vehicles and wind turbines in microgrid: a model predictive control approach. IEEE Trans Smart Grid 7(3):1537-1551
[82] Ravichandran A, Sirouspour S, Malysz P et al (2018) A chanceconstraints-based control strategy for microgrids with energy storage and integrated electric vehicles. IEEE Trans Smart Grid 9(1):346-359

[83] Tafreshi SMM, Ranjbarzadeh H, Jafari M et al (2016) A probabilistic unit commitment model for optimal operation of plug-in electric vehicles in microgrid. Renew Sustain Energy Rev 66:934-947

[84] Mortaz E, Valenzuela J (2017) Microgrid energy scheduling using storage from electric vehicles. Electr Power Syst Res 143:554-562

[85] Panwar LK, Konda SR, Verma A et al (2017) Operation window constrained strategic energy management of microgrid with electric vehicle and distributed resources. IET Gener Transm Distrib 11(3):615-626

[86] Contreras-Ocana JE, Sarker MR, Ortega-Vazquez MA (2017) Decentralized coordination of a building manager and an electric vehicle aggregator. In: Proceedings of 2017 IEEE power \& energy society general meeting, Chicago, USA, 16-20 July 2017, 9 pp

[87] Sherkari T, Golshannavaz S, Aminifar F (2017) Techno-economic collaboration of PEV fleets in energy management of microgrids. IEEE Trans Power Syst 32(5):3833-3841

[88] Nunna HSVSK, Battula S, Doolla S et al (2018) Energy management in smart distribution systems with vehicle-to-grid integrated microgrids. IEEE Trans Smart Grid 9(5):4004-4016

[89] Parkhe A (1993) Strategic alliances structuring: a game theoretic and transaction cost examination of interfirm cooperation. Acad Manag J 36:794-829

[90] Ko KS, Han S, Sung DK (2018) Performance-based settlement of frequency regulation for electric vehicle aggregators. IEEE Trans Smart Grid 9(2):866-875

[91] Amini MH, Moghaddam MP, Karabasoglu O (2017) Simultaneous allocation of electric vehicles' parking lots and distributed renewable resources in smart power distribution networks. Sustain Cities Soc 28:332-342

[92] Kazemi MA, Sedighizadeh M, Mirzaei MJ et al (2016) Optimal siting and sizing of distribution system operator owned EV parking lots. Appl Energy 179:1176-1184

Lefeng SHI received the Ph.D. degree in 2012 from Chongqing University, China. He works at Chongqing Normal Universtiy now as a associate professor. His research interests include the management mode design of smart grid.

Tong LV is a graduate student of Chongqing Normal University, China. Her research interests include the proliferation of high-tech products and optimizing the operation and investment of power systems.

Yandi WANG is a undergraduate of electrical energy systems in Shandong University, China. Her research interests include modeling and optimization electricity system operation. 